\title{
INTER-NEST INTERACTIONS, NEST AUTONOMY, AND REPRODUCTIVE SPECIALIZATION IN AN AUSTRALIAN ARID-ZONE ANT, RHYTIDOPONERA SP. 12
}

\author{
By P. Pamilo, ${ }^{1,2}$ R. H. Crozier, ${ }^{1}$ J. Fraser ${ }^{3}$
}

\section{INTRODUCTION}

Rhytidoponera sp. 12 ANIC is a large Australian ponerine ant which lacks a morphologically-differentiated queen caste. As is the case for many other Australian species in this genus, some of the workers mate and assume the egg-laying role. As has been inferred for species in the $R$. metallica complex (Haskins and Whelden, 1965 ) and observed for $R$. maniae (another large arid-zone species) and species in the $R$. impressa complex (Ward, 1981), colonyfounding under this life-pattern is probably usually accomplished by fission ("hesmosis"), in which one colony divides into two. Unlike the situation where nest-founding follows a dispersive mating flight, colony fission is likely to lead to the new nest being located close to the parent one, leading to a population structure in which neighboring nests are genetically related. A large study of the apportionment of genetic variation in a population of $R$. sp. 12 (Crozier et al., 1984) found that neighboring nests are indeed more similar genetically than expected by chance-they are related.

The finding (Crozier et al., 1984) that neighboring nests are related raises the question of colony boundaries. Does each nest represent a separate colony, or do daughter-nests remain socially connected after fission, forming polydomous (multi-nest) colonies? The two alternatives are not, of course, completely clear-cut, in that intermediates could occur between single-nest colonies and truly

'School of Zoology, University of New South Wales, Kensington, N.S.W. 2033 AUSTRALIA

Corresponding author: R. H. Crozier, School of Zoology, UNSW, P.O. Box 1, Kensington, NSW 2035 AUSTRALIA

2Present address: Center for Demographic \& Population Genetics, University of Texas Health Science Center at Houston, P.O. Box 20334, Houston, TX 77025, U.S.A.

3Biology Department, Boston University, 2 Cummington St., Boston, MA., 02215 U.S.A.

Manuscript received by the editor January 3, 1985. 
integrated polydomous colonies. Thus, there could be differing degrees of tolerance between the workers of neighboring nests, and various levels of worker exchange between nests.

Our study on intra-population genetic variation in $R$. sp 12 is a continuing one, the results for which will be reported elsewhere (Crozier et al., 1984, and in prep). In this paper we report observations on colony maintenance and inter-nest interactions, made with the intention of furthering our understanding of the extent of the reproductive division of labor within colonies, and the degree of nest autonomy in natural populations.

Rhytidoponera sp. 12 ANIC has also been referred to as $R$. mayri (Crozier et al., 1984) and as $R$. sp. B (Davidson and Morton, 1981). The acronym "ANIC" refers to provisional species recognised, but not yet named, by Dr. R. W. Taylor and held by the Australian National Insect Collection, maintained by the CSIRO Division of Entomology in Canberra (see Imai et al., 1977).

\section{MethodS AND Results}

Study site.

The population studied is in Conservation Paddock of the University New South Wales Arid Zone Research Station, north of Broken Hill, New South Wales, and is further described by Crozier et al. (1984).

The dominant ant with respect to competitive interactions in the study site is Iridomyrmex viridiaeneus, a colony of which is associated with a grove of Acacia victoriae in the center.

The observations reported here were made during September 17-28 and November 9-15, 1983, although preliminary observations have been made over a number of years in connection with the relatedness studies.

\section{Reproductive state}

The ant nests are in hard clay soil and data from a number of excavations indicate that the lowest gallery reaches a depth of about $1 \mathrm{~m}$ below ground level. We excavated two nests completely; one of these was a mature nest (excavated on November 15), in that it went down to the usual depth, whereas the other was an incipient colony (we observed it being established and it only achieved a depth of ca. $16 \mathrm{~cm}$ ) excavated on September 21. 
Ants were taken from the mature nest in two groups which were kept separate. The excavation took place during the middle of the day, with surface temperatures in excess of $45 \mathrm{C}$, so that no ants would have been expected to be absent foraging. We first extracted ants by "fishing" them from the nest entrance using straws. When no more ants could be obtained by this method, we dug the nest up, carefully checking all the side tunnels for ants as we went. Fishing yielded 192 ants and digging 245 . The excavated ants consisted of 107 mature ants and 138 young ones (as determined by their exoskeletons being soft and them lacking abdominal white or yellow bodies). We also found 243 cocoons and 11 larvae. Of the cocoons, 235 contained worker pupae, one contained a male pupa, and seven had unclassifiable larvae or prepupae.

The adult ants were dissected and checked for ovarian status and whether or not the spermatheca (sperm storage device) contained sperm. All of the young ants were found to be non-inseminated upon dissection, and also lacked corpora lutea. Their ovaries were either quite undeveloped, or very poorly developed in terms of possessing oocytes in the ovarioles. The results of dissecting the old ants are shown in Table 1. Inseminated ants occurred significantly more often among the ants obtained by digging than those obtained by fishing $(G=37.26$ (Yate's correction), $p<0.001)$. The one inseminated worker caught by fishing was unusual for an inseminated worker in having no empty ovarioles, but this state is the predominant one among uninseminated workers. We therefore tentatively discount this ant as an established egg-layer, leading to an estimate of 22 egg-layers, or $7.4 \%$ of the worker force.

Pooling empty-ovariole classes 1-5 reveals marked differences in ovarian status between the various categories of ants shown in Table 1. Thus there is a significant difference among the uninseminated ants between those collected by fishing and those collected by digging $\left(X^{2}=14.6, p<0.001\right)$, and, among the ants collected by digging, between those inseminated and those not $\left(\mathrm{X}^{2}=74.7, \mathrm{p}<\right.$ 0.001 ). The uninseminated ants collected by digging had, on average, less-developed ovaries than the uninseminated ants collected by fishing. The inseminated ants are characterised by belonging to the classes with intermediate (1-5) numbers of empty ovarioles, and also had an intermediate number of oocytes per ovariole.

The incipient colony examined was discovered through carrying being observed to it from an established nest about $5 \mathrm{~m}$ away. The 
Table 1. Reproductive status of inseminated and non-inseminated ants from a mature colony in terms of the number of ovarioles per ant which lacked oocytes. Ants were further classifiable into those collected before the nest was dug up (by "fishing") and those collected during excavation.

\begin{tabular}{lrrrrrrrrr}
\hline & \multicolumn{8}{c}{ Number of empty ovarioles } \\
& 0 & 1 & 2 & 3 & 4 & 5 & 6 & Total \\
\hline $\begin{array}{l}\text { Non-inseminated } \\
\quad \text { fished }\end{array}$ & 111 & 8 & 7 & 2 & 3 & 7 & 53 & 191 \\
excavated & 68 & 1 & 0 & 1 & 0 & 0 & 15 & 85 \\
& & & & & & & & \\
$\begin{array}{l}\text { Inseminated } \\
\quad \text { fished }\end{array}$ & 1 & 0 & 0 & 0 & 0 & 0 & 0 & 1 \\
$\quad$ excavated & 3 & 1 & 10 & 6 & 1 & 1 & 0 & 22 \\
\hline
\end{tabular}

ants collected from it were packed tightly into the limited gallery space available. We dissected 230 ants from the incipient colony; about 30 more died before they could be dissected. None of the ants dissected were inseminated. The distribution of empty ovarioles for these individuals is shown in Table 2; it resembles that of the uninseminated ants collected by digging from the mature colony (Table 1), although it should be remembered that these two nests were collected almost two months apart. We found no eggs or larvae in the incipient colony, although partial excavations of mature colonies at that time yielded small larvae.

\section{Foraging interactions}

The nests in the study area are overdispersed (Crozier et al., 1984), suggesting that there is foraging competition (Levings and Traniello, 1981). Given the relatedness between neighboring nests, and this a priori evidence for competition, investigation of various aspects of foraging behavior that pertain to these factors was carried out.

We studied the foraging characteristics of one nest (number 54 in our system) in both September and November. The vegetation in the study area, chiefly herbaceous, was considerably more abundant in September than in November, with plants of Tetragonia tetragonioides (New Zealand Spinnache) being numerous in September but largely absent in November. This plant appeared to be particularly significant as a food plant for caterpillars, a major prey item. Even in September, however, the overall cover was not thick, with $33.7 \%$ of the ground bare, $58.1 \%$ covered by sparse herbs, $6.7 \%$ with a 
Table 2. Reproductive status of ants from an apparent incipient colony, in terms of the number of ovarioles per ant lacking oocytes. No inseminated ants were found during dissections from this group.

\begin{tabular}{cccccccccc}
\hline \multicolumn{1}{c}{ Number of empty ovarioles } \\
0 & 1 & 2 & 3 & 4 & 5 & 6 & Total \\
\hline 166 & 17 & 12 & 16 & 10 & 6 & 3 & 230 \\
\hline
\end{tabular}

medium cover, and $1.5 \%$ with a relatively dense herbaceous cover.

We determined the foraging area of nest 54 by following individual foragers and marking the points at which they turned back for the nest (whether they had obtained a food item or not). The distributions (Table 3 ) of these most-distant points of foraging trips differed significantly $\left(X^{2}=9.59\right)$ between September and November, with the trip-distances in November being longer. This difference may be due to differences in the success rates of foraging trips: although we did not record successes and failures, it was readily apparent that a majority of trips in September resulted in collection of a food item, whereas most November trips ended with ants returning unladen. Most food items were brought back to the nest by individual workers, but very rarely large items such as large (ca. 5 cm long) crickets were retrieved by groups; the mechanism of recruitment is unknown but may involve short-range communication via the powerful stridulation mechanism these ants possess.

The extent of the overlap between the foraging areas of adjacent nests cannot be quantified in the absence of data, such as in Table 3, collected for adjacent nests simultaneously, but it is clearly considerable, in that many ants walked beyond the edge of the figure described around their home nest by its neighbors (figure 1).

To determine the extent to which individual workers show fidelity in foraging direction over several trips we marked individual foragers from two nests (54 and 6) and subdivided the nest environs into eight equal-sized radial sectors. We recorded the sectors in which each marked individual foraged. The extent of fidelity can then be

Table 3. Most distant points reached during individual foraging trips from nest 54 during the two observation periods.

\begin{tabular}{lccccc}
\hline & $0-5 \mathrm{~m}$ & $5-10 \mathrm{~m}$ & $10-15 \mathrm{~m}$ & $>15 \mathrm{~m}$ & Total \\
\hline September & 6 & 20 & 10 & 2 & 38 \\
November & 6 & 16 & 22 & 13 & 57 \\
\hline
\end{tabular}


measured by the distribution of sector-numbers pertaining to the trips observed. The difference between two successive foraging trips is zero if the ant selects the same sector each time (showing perfect fidelity), four if she takes opposite sectors, and on average two if she selects foraging sectors at random. We obtained records of three or more trips for some individuals, but, for simplicity of analysis, only used two in our calculations, using the first and the last where several data were available for one individual. The mean difference for nest 6 was 1.57 (based on seven foragers) and 1.24 (based on 25

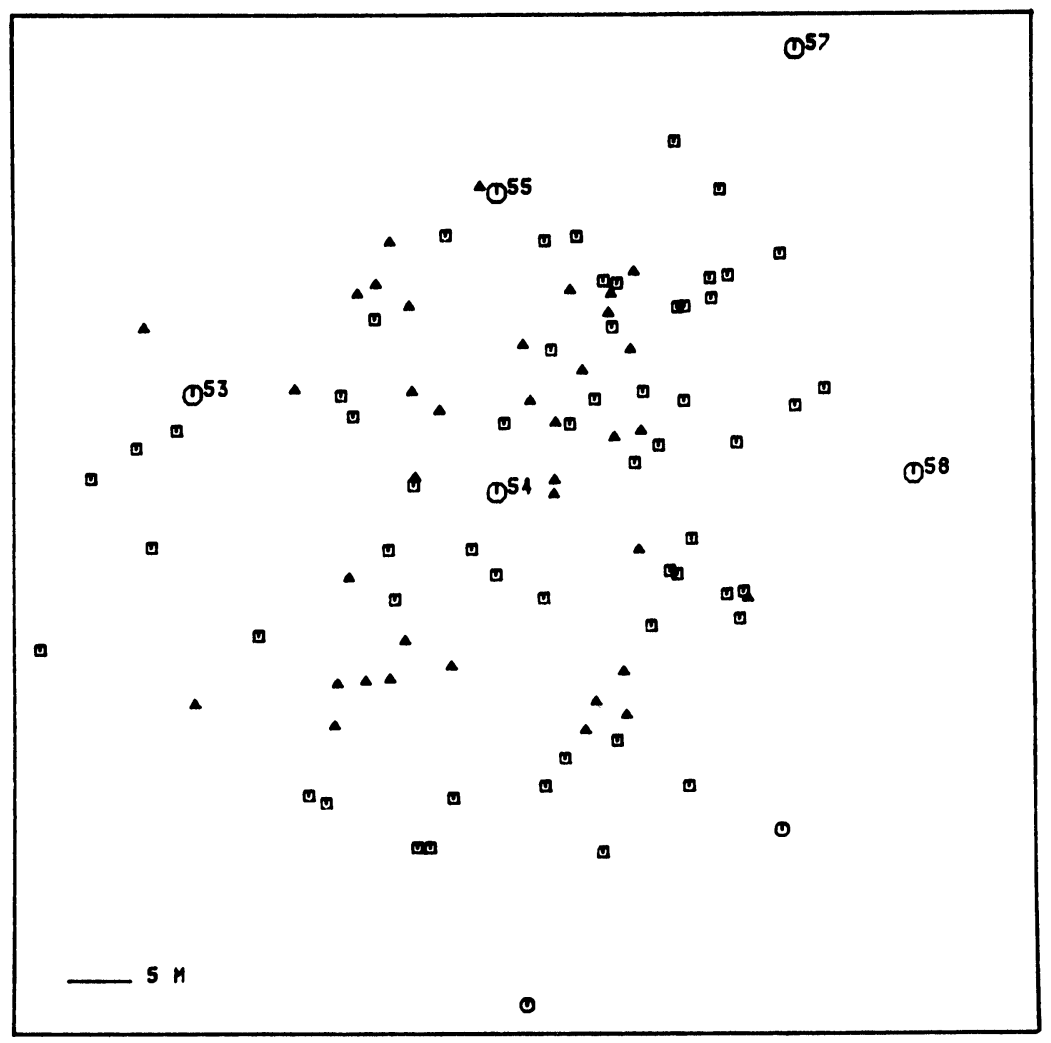

Fig. 1. Furthest points reached by foraging ants from nest 54 during the September (closed triangle) and November (open square) observation periods. Octagons denote active nests, with numbers referring to those given in the relatedness study (Crozier et al., 1984). 
foragers) for nest 54. For both nests we calculated the expected mean sector-difference according to random expectation using the actually-observed distribution of trips between sectors (because some sectors were visited more than others). In both cases, the mean sector-difference observed was significantly less, at the $95 \%$ level, than that under random expectation. These findings indicate shortterm foraging-direction fidelity, but we do not know how long this fidelity persists, or if it occurs at other times of the year, nor whether the success or failure of a foraging trip influences the sector chosen subsequently.

We observed several instances in which foraging ants from different nests encountered each other in the field. In each case they reacted with apparent alarm or hostility to such ants, but not to nestmates. Foragers from different nests often ran away from each other, but on occasion fought, using their mandibles and stings. Seized ants stridulated. When such encounters occurred close to one or other nest, the ant from that nest was sometimes joined by a nest-mate. In that case, the two ants sometimes dragged the third further away before releasing it, but at other times dragged it into the nest. Ants dragged into an alien nest are not necessarily killed: we observed that one ant (not necessarily alien) was dragged out of one nest and released $2 \mathrm{~m}$ away.

\section{Inter-nest movements.}

We observed ants moving between nest sites in three sections of the study area. Two of these instances involved the establishment of a new nest, one of which was dug up and the ants dissected, as reported above; the third involved movement between old, inhabited nests. In each case, many ants were carried between nests by others; such ants moved in pairs, one carrying the other over its head, grasped by the mandibles. We concentrated our observations on the case involving the movement between long-established nests. To speed our subsequent discussion, and following established practice, we will term this phenomenon "carrying", and distinguish the ant carrying the other as the "carrier", and the ant being transported as the "recruit". Such carrying has been described for other Rhytidoponera species (Möglich and Hölldobler, 1974; Ward, 1981).

We first observed carrying occurring from nest 59 to nest 60 on September 17, and this activity continued at a high level for the entire September observation period (11 days) and was also seen in 


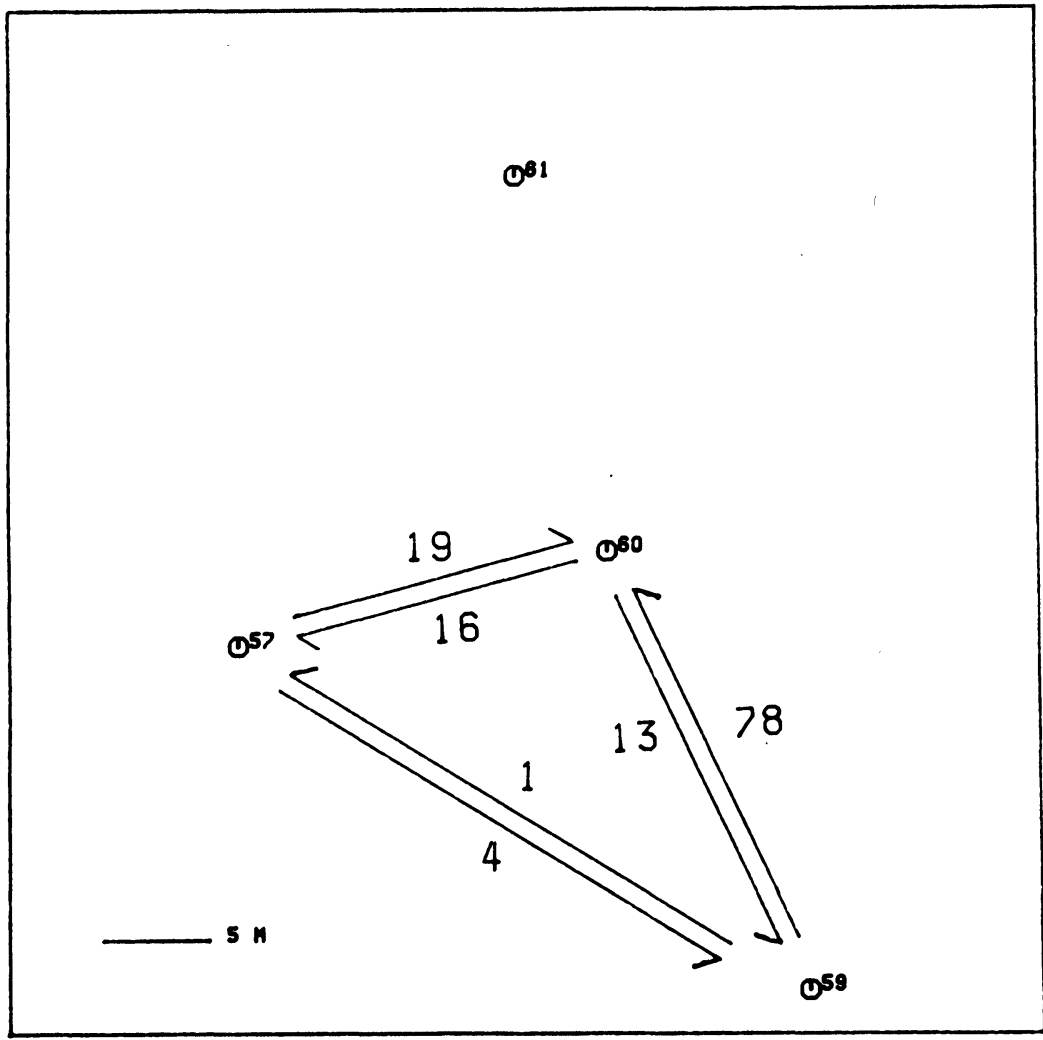

Fig. 2. Positions of nests involved in internest transfers in September. The arrows give the direction taken by observed carrier/recruit pairs, and the figures beside the arrows the numbers of such observations. Thus, most activity involved nest 60 , with $60 \%$ of all observed carrier-recruit pairs moving to it from nest 59.

November. It soon became clear that carrying was occurring between nests 59,60 and 57 , and such movements occurred in each of the possible directions. But the predominant direction remained, as shown in figure 2, from nest 59 to nest 60 (involving $60 \%$ of all observations of carrying). The fidelity of carrying direction was high; during our observation periods we saw only one carrier change the nest it used as a destination. While it is likely that carrying started before we first observed it, it is our impression that it started first with nests 59 and 60 , with nest 57 becoming involved later. 
We used model paints to mark ants distinctively according to the nest in which they were caught, and could thus trace the flow of ants during inter-nest movements and evaluate the degree of mixture of ants from different (original) nests. Table 4 shows that this mixture was very considerable, and also reflects the fact that most ants in the three nests had moved into nest 60 by the end of the second observation period.

Carrying was also observed during our November visit to the study site, although it did not appear to be as frequent as in September. In November we observed ants being carried from nests 59 and 57 to nest 60 , and also observed ants moving between these nests without carrying or being carried. Transport of brood was also seen, once in September. Although, in September, the ants of nest 61 were markedly hostile to ants from nests 57,59 and 60 , marked ants from all of these nests were found in nest 61 during November.

Carrying took place at times of high activity of ants outside the nests (i.e., during foraging sessions). These times, during our observation periods, were in the morning and late afternoon. At times, carrying became an activity rivaling foraging, with many ants emerging from nest 60 and heading towards the neighboring nests. These carriers mostly brought ants back from the other nests; seldom did they take ants to them.

Marking of carriers and riders showed that these two categories

Table 4. Mark-recapture observations on nests 57, 59 and 60 . Ants were marked with paint dots according to whether they were found in nest $57(\mathrm{O}=$ orange), 59 (W $=$ white), or $60(G=$ green $)$. At the end of the September observation period, as many ants as possible were captured from each nest, and the colors of the marked ants noted before all ants were returned to the nests they were last captured in. The decline in the number of marked ants in November is mostly due to loss of the marks rather than to mortality. The numbers in the table are of the ants recaptured; percentages of the total captured in each nest for each color are shown beneath each number.

\begin{tabular}{lcccrrrrrr}
\hline & \multicolumn{3}{c}{ Sept. 20 } & \multicolumn{3}{c}{ Sept. 28 } & \multicolumn{3}{c}{ Nov. 14 } \\
Nest & O & W & G & O & W & G & O & W & G \\
\hline $57(0)$ & 39 & 0 & 1 & 14 & 2 & 5 & 1 & 0 & 0 \\
& 97.5 & 0 & 2.5 & 65 & 10 & 25 & & & \\
$59($ W) & 0 & 82 & 5 & 6 & 29 & 3 & 0 & 0 & 0 \\
& 0 & 94 & 6 & 16 & 76 & 8 & & & \\
$60(G)$ & 3 & 11 & 47 & 20 & 64 & 41 & 2 & 13 & 5 \\
& 4 & 18 & 78 & 16 & 51 & 33 & 10 & 65 & 25 \\
\hline
\end{tabular}


are distinct: carriers form a specialized group. For example, we observed 11 carriers make 40 transport trips from nest 59 to 60 . The differences between carriers and recruits extended to physiological state, with carriers having relatively poorly-developed ovarioles (Table 5).

Fukumoto and Abe (1983) found recruits to be indoor, and carriers to be outdoor, ants in the ponerine Diacamma rugosum, but the observation in Formica suggest that the carriers have an intermediate position between the two groups (Rosengren, 1971). We therefore attempted to demonstrate differences in the laboratory between carriers and recruits of Rhytidoponera sp. 12 in their preferences for darkened as against lit conditions. Ten ants from each group were individually placed into chambers made of two test tubes connected at their openings. One test tube was shaded using foil, and the other left uncovered. Each ant was allowed to select the dark or the light section of the chamber, and nine readings were made on each ant at half-hour intervals changing which end was shaded after each reading. The difference between the carriers and recruits is in the direction expected although ranking the two series of ants does not quite reveal a statistically significant result (the value of the MannWhitney test statistic comparing the two distributions from Table 6 is 72.5 ; whereas the value for the $5 \%$ level of a one-tailed test is 73 , and for the $10 \%$ level it is 68 ).

\section{Hostility tests.}

Although ants from different nests often fight when they meet as foragers, the carrying phenomenon indicates that there must be considerable variation in the degree of hostility depending on the nests involved. We attempted to quantify the degree of hostility between different nests by moving ants between them.

Trials in previous years using mutton baits had been highly successful in moving ants between nests with minimal disturbance. This method, however, proved hard to quantify and had to be aban-

Table 5. Ovary development in carrier versus recruit ants collected during movements between colonies.

\begin{tabular}{lccccccccc}
\hline & \multicolumn{8}{c}{ Number of empty ovarioles } \\
& 0 & 1 & 2 & 3 & 4 & 5 & 6 & Total \\
\hline carriers & 2 & 1 & 1 & 1 & 1 & 0 & 9 & 15 \\
recruits & 23 & 1 & 3 & 0 & 0 & 1 & 4 & 32 \\
\hline
\end{tabular}


Table 6. Behavioral comparison of carrier and recruit ants collected during internest movement: number of observation periods (out of nine) that ants were seen in the lit halves of choice chambers. Each series of observations on 10 individual ants in the two categories has been ranked.

\begin{tabular}{lllllllllll}
\hline & \multicolumn{10}{c}{ Ant rank } \\
& 1 & 2 & 3 & 4 & 5 & 6 & 7 & 8 & 9 & 10 \\
\hline Carriers & 0 & 4 & 6 & 7 & 7 & 8 & 8 & 8 & 9 & 9 \\
Riders & 1 & 1 & 2 & 2 & 4 & 5 & 5 & 6 & 8 & 9 \\
\hline
\end{tabular}

doned in 1983 anyway because the ants showed no interest in mutton baits during our visits then. We chose not to use the method described by Haskins and Haskins (1983) for tests with $R$. metallica, in which individual ants from different nests are placed together in glass containers, because in that case both ants have been removed from their natural surroundings. Instead, we picked up an ant from one nest, grasping it by a mid-femur using forceps, and held it in the entrance of a target nest until four residents had examined it. If any of these attacked the transferred ant, the result was taken as a rejection of this ant. Five ants in all were used sequentially for each test, and, wherever allowed by the numbers of ants available, tests were made reciprocal. Because our method creates an artificial situation and the response at the nest entrance can be largely induced by the introduced ant, we also tested the method by making a control test at each nest, returning ants to their home nest: these ants were never attacked.

During any one test, results were usually fairly unequivocal. Even when ants attacked the forceps vigorously, they often ignored the transferred ant. However, we found a high degree of variation between replicates (Table 7), which may reflect differences in the responsiveness of the ants under varying environmental conditions (which we could not readily control). Nevertheless, some patterns do emerge. Thus, nest 61 was markedly more hostile to the "carrying" nests in September than in November, reflecting the significant turnover of ants between those times. Similarly, nest 60 shows elevated acceptance levels compared to other nests.

The results at nest 55 may have been affected by the fact that the mound was destroyed by some animal (probably a kangaroo) at the beginning of our experiments in September and the ants were busy rebuilding it. 
Table 7. Hostility test results. Five ants in turn were taken from one nest to another and held by a mid-femur with forceps in the entrance of the "host" nest. An ant was considered "accepted" if at least three ants from the host nest contacted it without attacking it. The figures are the number of ants out of each set of five which were thus "accepted". Slashes separate results from repeated tests. The tests were carried out first in September and then repeated, where possible, in November. Dashes indicate tests that could not be done because of a shortage of ants at the surface of the nest of origin.

\begin{tabular}{lcccccccccc}
\hline \multirow{2}{*}{ Host } & \multicolumn{1}{c}{$\begin{array}{c}\text { Nest of Origin } \\
\text { September }\end{array}$} & 54 & 55 & 57 & 58 & 59 & 60 & 61 & 63 & 64 \\
\hline & 54 & 5 & $5 / 1$ & $0 / 3 / 2$ & 0 & - & 1 & 2 & 1 & 0 \\
& 55 & 5 & 5 & - & 4 & - & 4 & 4 & 5 & 4 \\
& 57 & $5 / 0$ & - & 5 & - & 3 & 5 & $5 / 0$ & - & - \\
& 58 & 0 & 1 & - & 5 & - & 1 & 3 & 1 & 3 \\
& 59 & - & - & - & - & 5 & 5 & - & - & 5 \\
& 60 & 5 & 5 & 4 & 4 & 5 & 5 & 4 & 4 & 4 \\
& 61 & 0 & 3 & $1 / 0$ & 1 & - & $1 / 0$ & 5 & $5 / 1$ & $4 / 2$ \\
& 63 & 2 & 1 & - & 0 & 1 & 0 & 3 & 5 & 0 \\
& 64 & 0 & 0 & - & $4 / 0$ & 0 & 1 & 1 & 2 & 5 \\
\hline \multirow{5}{*}{ November } & 54 & 5 & 4 & 5 & 1 & - & 5 & 4 & 4 & 4 \\
& 55 & 0 & 5 & 2 & 2 & - & 1 & 3 & 5 & 3 \\
& 57 & 3 & 1 & 5 & 3 & - & 5 & 5 & 2 & 5 \\
& 58 & 0 & 2 & 4 & 5 & - & 1 & 0 & 3 & 3 \\
& 60 & 4 & 2 & 5 & 1 & - & 5 & 5 & 3 & 5 \\
& 61 & 0 & 0 & 5 & - & - & 5 & 5 & - & - \\
& 63 & 2 & 1 & 5 & 2 & - & 5 & 1 & 5 & 5 \\
& 64 & 1 & 0 & 1 & 1 & - & 1 & 0 & 0 & 5 \\
\hline
\end{tabular}

\section{Discussion}

Of the ants we excavated from the mature colony, 299 were old ants and 138 had emerged relatively recently. The number of true egg-layers was 22, yielding estimates of these being $7.4 \%$ of the mature ants, or $5.0 \%$ of the total worker force. Whelden (1957) dissected 274 ants of a relatively closely-related species, $R$. violacea, and found 22 of these to be inseminated. Unfortunately, Whelden does not record the numbers of mature versus callow ants, although he does mention the presence of some of the latter. His figure of $8.0 \%$ of the workers being inseminated is therefore not directly comparable to our estimates, because his collection was made in May (a late autumn month in Australia) whereas ours was made in November, an early summer month. 
The average relatedness level of $0.158( \pm 0.037,95 \%$ confidence limits) for this $R$. sp. 12 population (Crozier et al., 1984) would suggest that the average number of egglayers per nest yielding workers would be 5.8 (with $95 \%$ confidence limits 4.6-7.9), according to the formulas of Pamilo and Varvio-Aho (1979) and under the assumptions that these egg-layers are as closely related as workers on average, that they mate once and to unrelated males, and that they contribute equally to the next generation. The figure of 22 we observed requires confirmation by further excavations but, if confirmed as typical, would indicate that one or more of these assumptions are violated. If 22 mated workers did contribute to the next generation under these assumptions, then the mean relatedness level would be below 0.05 .

Data are also available for Rhytidoponera species with lifepatterns differing to that of sp. 12 with regard to the observed proportions of mated workers. Haskins and Whelden (1965) found $5.4 \%$ of the workers to be inseminated in R. metallica and $2.3 \%$ in $R$. inornata, both species that habitually lack differentiated queens in their colonies, but in which winged queens do occasionally occur. Ward (e.g., 1981, 1983) found that species in the impressa group have colonies of two kinds: those with a single differentiated queen each, and those lacking such queens but in which the reproductive role is taken over by some mated workers, as in sp. 12. Figures reported by Ward (1983) for 33 colonies of the latter type in confusa and chalybaea yield an estimate of $3.7 \%$ of the workers being inseminated. While the various Rhytidoponera species may differ in the percentages of workers per colony that are inseminated, little can be inferred from the figures so far, because it is likely that the percentage varies with age and size of colonies, and with the time of the year collections are made, and these data are imperfectly recorded in the literature.

The occurrence of oocytes in the ovarioles of most ants, mated or not, is striking. Whelden (1957) mentions that many workers in violacea have oocytes, and that the occurrence of oocytes is not linked to that of sperm in the spermatheca, but he gives no figures. Ward (1983) found much smaller percentages of unmated workers to have oocytes in impressa-group colonies. We suggest that the eggs of uninseminated workers are probably trophic eggs, eggs laid only to be eaten. Nutrient transfer by this means is common in the 
colonies of ants and other social Hymenoptera, and has its precursors in presocial insects (Wilson, 1971: 279-281). However, the oocytes of unmated sp. 12 workers did not appear different morphologically to those of inseminated individuals, whereas in some ant species at least trophic eggs differ in size, consistency, or both, from reproductive eggs (Wilson, 1971: 279-281).

The life pattern of Rhytidoponera species such as sp. 12 and violacea, in which the differentiated queens regarded as normal among ants are replaced by mated workers, is paralleled in many other ants. Wheeler and Chapman (1922) provided the first such observation, for the ponerine Diacamma rugosum, Haskins and Zahl (1971) showed that another ponerine, Dinoponera grandis is very similar, and a further ponerine, Ophthalmopone berthoudi, has recently been examined intensively (Peeters, 1982; Peeters and Crewe, 1984). Whereas the ponerine workers all resemble each other closely, those of another ant with mated workers, the myrmicine Harpagoxenus sublaevis, vary in size and thoracic development, and only about $4 \%$ of them possess a spermatheca: the mated workers form a majority of this $4 \%$ (Buschinger and Winter 1975, 1978). True queens also occur in $H$. sublaevis; whether a female larva has the capacity to develop as a queen or as a worker is determined genetically (Buschinger 1978). Workers lack spermathecae in Harpagoxenus canadensis and in H. americanus (Buschinger and Alloway 1977, 1978), preventing the evolutionary replacement of true queens by mated workers in these species; in all three species unmated workers may also oviposit. A major difference between the ponerine mated worker system and that of $H$. sublaevis is that $H$. sublaevis colonies possess only one mated egg-layer each, whether a worker or a true queen, whereas the ponerines can have many such individuals per colony. The polymorphism of mated egg-layers in Rhytidoponera species such as metallica and confusa, and in Harpagoxenus sublaevis, and the apparent morphological identity of all workers, mated or not, in the ponerines, indicates that the mated workers are fundamentally different in evolutionary origin and present-day caste-determination dynamics to the ergatoid queens of genera such as Myrmecia and Dorylus, with ergatoids differing morphologically from workers in the direction of true queens and representing intergrades. Wilson's (1971: 138-139) distinction between queens (as fully-developed reproductive females with func- 
tional though deciduous wings) and ergatogynes (queen-worker intermediates) is useful as a description of significantly-different biologies for the egg-layer role, and the mated workers we have discussed represent a third important type. We concur with the felicitous term of gamergate proposed for them by Peeters and Crewe (1984).

The factors leading a Rhytidoponera worker to become a gamergate or not are unknown. Peeters and Crewe (1984) found percentages of gamergates much higher for Ophthalmopone (up to 63\%) than reported for Rhytidoponera, and suggested that the wide variability of this percentage during the year indicates that the determination of gamergates in Ophthalmopone is purely a matter of whether or not males are available during a crucial period during the early period of a worker's life. This idea remains to be tested for Rhytidoponera, but a major difference between the two genera is already known: a majority of Rhytidoponera workers have ovarian activity, whereas only gamergates possess oocytes in Ophthalmopone. Gamergates in both genera, however, are similar in being found in the nest and not outside.

Foraging appears to be a rudimentary type-II type in the classification of Oster and Wilson (1978: 248-251): workers diffuse out from the nest and mostly act individually, but are capable of at least short-range recruitment when difficult food items are located. Concerted defense of territory is lacking, although a kind of "defense in depth" operates: the further workers penetrate into the foraging areas of neighboring colonies, the more likely they are to encounter workers from these colonies and undergo potentially-deadly combat. However the density of ants is not high enough to make such contact invariable, and this is reflected in the fact that many foraging trips approach or exceed the line subtended by neighboring nests. Nevertheless, we would expect that workers would tend to avoid areas heavily patrolled by hostile ants, although the data are not numerous enough to test this hypothesis.

The finding that foragers tend to choose the same direction in repeated trips is consistent with our expectation that the worker force would tend to avoid areas patrolled particularly heavily by those of neighboring nests, in that such a capacity for recollection is needed for the avoidance mechanism to operate. Foraging direction fidelity of the same kind as in $R$. sp. 12 has also been demonstrated 
in the myrmicine harvesters Pogonomyrmex barbatus, $P$. maricopa (Hölldobler 1976), and P. mayri (Kugler, 1984); another myrmicine harvester, Pheidole militicida (Hölldobler 1976; Hölldobler and Möglich 1980), and various formicines such as Formica species (Rosengren, 1971: 7-57), show route fidelity: tendency of workers to exit along the same trunk route in successive trips. It is possible that foragers of these species and of $R$. sp. 12 not only forage in the same direction in successive trips, but also visit the same areas in the foraging grounds, as has been demonstrated for foragers and aphidtenders of the formicines Cataglyphis bicolor (Harkness and Harkness 1976), Formica obscuripes (Herbers 1977), Formica yessensis (Higashi 1978), F. subnuda, F. subsericea and Camponotus noveboracensis (Ebbers and Barrows 1980): the phenomenon of ortstreue (Oster and Wilson 1978: 152).

Among ponerines, carrying has also been implicated in nestmoving in Diacamma rugosum (Fukumoto and Abe, 1983), Bothroponera tesserinoda (Maschwitz et al., 1974; Möglich and Hölldobler, 1974), and Ophthalmopone berthoudi (Peeters, 1984). However, D. rugosom also employs tandem running and in $B$. tesserinoda tandem running is the chief method used.

The extensive "carrying" between nests indicates that, although considerable hostility can be demonstrated both between foraging workers and by our "hostility tests", such internest hostility is not invariable. We are uncertain at present whether certain groups of nests are linked as multinest colonies, or whether the situation might not be more complex. It is possible, for example, that the fundamental selection unit above that of the individual in populations such as that of the observed $R$. sp. 12 and of some Formica species (Scherba 1964) is not the nest but the matriline or sibship. Nests would contain cooperating matrilines, and carrying may represent attempts to maintain nests at adequate strength via the antnapping of outsiders. The rather confused nature of carrying, with workers making trips in several different directions, is consistent with the matriline-selection hypothesis, but is also observed in some other ants during nest-moving when scouts "choose" different destinations (Möglich and Hölldobler 1975; Rosengren and Pamilo 1983), and such multi-directional carrying can be likened to a voting system for choosing the best nest-site (Rosengren, 1971: 21; Wilson, 1971: 224). The observation of ants marked in the 57-59-60 system in nest 61 in 
November, whereas ants from nest 61 had been uniformly hostile to such ants in September, is not, however, consistent with the hypothesis of a multinest colony. That moving in $R$. sp. 12 rests on the pronota of elite movers is consistent with observations from other ants (Möglich 1978; Möglich and Hölldobler 1974, 1975), as is the observation of reduced ovarian activity in these mover workers (Möglich and Hölldobler 1975). Carrier ants may not, of course, be acting in the "interests" of those carried: carrying in Formica aquilonia (Rosengren and Pamilo 1983) can represent the robbing of workers by one nest of another (closer to true slavery than is dulosis).

If carrying is an "amicable" activity, then it might be expected to occur between nests more closely related than the average. The analyses so far available (Crozier et al 1984) cannot yield that information, because the relatedness estimates are regression coefficients pertaining to the population as a whole. But the determination of genetic distances between colonies, based on further data, may overcome this lack.

\section{ACKNOWLEDGEMENTS}

This work was supported by a grant from the Australian Research Grants Scheme to RHC. We also thank the US National Science Foundation for a travel grant making JF's participation possible, and Dr. C. Carter, Officer in Charge of Fowler's Gap Research Station, for providing general aid and assistance, and for identifying a plant species.

\section{SUMMARY}

We report studies on the reproductive and foraging biology of Rhytidoponera sp. 12, a large ponerine ant which lacks a morphologically-differentiated queen caste.

Based on dissections of 437 ants from an established colony, about $7.5 \%$ of the mature workers are mated egglayers (equivalent to the gamergates of Peeters and Crewe, 1984). These mated workers are concentrated in the lower regions of the nest, or move preferentially to them during disturbance. Workers taken from the upper regions of the nest had low levels of ovarian activity whereas unmated workers from the lower regions had high such levels; 
mated workers showed intermediate activity. We suggest that the oocytes of unmated workers may be destined to become trophic eggs.

None of the 230 ants dissected from an apparently incipient colony was inseminated; the level of ovarian activity in such individuals was high.

Foragers from different nests were not indifferent to each other after contact, usually running away but sometimes fighting. Despite this antagonism between foragers, the foraging area for two nests studied intensively extended beyond the figure subtended by neighboring nests. Foraging trips extended significantly further in November than in September, probably due to a decline in the food supply.

Foragers had a strong and statistically significant tendency to take the same direction in successive foraging trips, i.e., they show foraging-direction fidelity.

We saw ants carrying others from one nest to another in three regions of our study area, and studied their behavior in one of these areas intensively. In this region, we saw this carrying take place in September in each of the possible six directions between three nests. But most traffic was into one of them, nest 60 . The resulting intermixture of ants between nests was considerable, as shown by marking experiments. Tests for worker hostility to ants from other nests showed nest 60 to be the least hostile, with the adjacent nest 61 , not one of the three nests linked by carrying, showing a high level of intolerance to strangers. In November, however, nest 61 included ants originally marked in the other three nests.

"Carrier" ants had less ovarian activity than those they carried, and, from the additional fact that the same carriers made repeated trips, seem to form a relatively small group within the colonies.

It is uncertain whether the nests linked by internest movements represent multi-nest colonies, or whether such activity can potentially involve any neighboring nests.

\section{Literature Cited}

Buschinger, A. 1978. Genetisch bedingte Einstehung gefluegelter Weibchen bei der sklavenhaltenden Ameise Harpagoxenus sublaevis (Nyl.) (Hym., Form.). Insectes Sociaux, 25: 163-172.

Buschinger, A., ANd T. M. Alloway. 1977. Population structure and polymorphism in the slave-making ant Harpagoxenus americanus (Emery) (Hymenmopteran: Formicidae). Psyche, 83: 233-242. 
Buschinger, A., And T. M. Alloway. 1978. Caste polymorphism in Harpagoxenus canadensis M. R. Smith (Hym., Formicidae). Insectes Sociaux, 25: 339-250.

Buschinger, A., ANd U. Winter. 1975. Der Polymorphismus der sklavenhaltenden Ameise Harpagoxenus sublaevis (Nyl.). Insectes Sociaux, 22: 333-362.

Buschinger, A., AND U. Winter. 1978. Echte Arbeiterinnen, fertile Arbeiterinnen und sterile Wirtweibchen in Voelkern der dulotischen Ameise Harpagoxenus sublaevis (Nyl.) (Hym., Form.). Insectes Sociaux, 25: 63-78.

Crozier, R. H., P. Pamilo and Y. C. Crozier. 1984. Relatedness and microgeographic genetic variation in Rhytidoponera mayri, an Australian arid-zone ant. Behav. Ecol. Sociobiol. 15: 143-150.

Davidson, D. W., AND S. W. Morton. 1981. Myrmecochory in some plants (F. Chenopodiaceae) of the Australian arid zone. Oecologia, 50: 357-366.

EbBers, B. C. AND E. M. BarRows. 1980. Individual ants specialize on particular aphid herds (Hymenoptera: Formicidae; Homoptera: Aphididae). Proc. Ent. Soc. Wash., 82: 405-407.

Fukumoto, Y., AND T. ABE. 1983. Social organization of colony movement in the tropical ponerine ant, Diacamma rugosum (Le Guillou). J. Ethol., 1: 101-108.

HARKNESS, M. L. R., AND R. D. HARKNESS. 1976. Functional differences between individual ants (Cataglyphis bicolor Fab.). J. Physiol., 258: 124P-125P.

HASKINS, C. P., AND E. F. HASKINS. 1983. Situation and location-specific factors in the compatability response in Rhytidoponera metallica (Hymenoptera: Ponerinae). Psyche, 90: 163-174.

Haskins, C. P., AND R. M. Whelden. 1965. "Queenlessness", worker sibship, and colony versus population structure in the formicid genus Rhytidoponera. Psyche 72: 87-112.

HASKINS, C. P., AND P. A. ZAHL. 1971. The reproductive pattern of Dinoponera grandis Roger (Hymenoptera, Ponerinae) with notes on the ethology of the species. Psyche, 78: 1-11.

Herbers, J. 1977. Behavioral constancy in Formica obscuripes (Hymenoptera: Formicidae). Ann. Entomol. Soc. Amer., 70: 485-486.

Higashi, S. 1978. Task and areal conservatism and internest drifting in a red wood ant Formica (Formica) yessensis Forel. Japan J. Ecol., 28: 307-317.

HOLldoBler, B. 1976. Recruitment behavior, home range orientation and territoriality in harvester ants, Pogonomyrmex. Behav. Ecol. Sociobiol., 1: 3-44.

Holldobler, B., AND M. Moeglich. 1980. The foraging system of Pheidole militicida (Hymenoptera: Formicidae). Insectes Sociaux, 27: 237-264.

Imai, H. T., R. H. Crozier and R. W. Taylor. 1977. Karyotype evolution in Australian ants. Chromosoma, 59: 341-393.

Kugler, C. 1984. Ecology of the ant Pogonomyrmex mayri: foraging and competition. Biotropica 16: 227-234.

Levings, S. C., AND J. F. A. Traniello. 1981. Territoriality, nest dispersion, and community structure in ants. Psyche, 88: 265-319.

Maschwitz, U., B. Hollddobler, AND M. MÖGlich. 1974. Tandemlaufen als Rekrutierungsverhalten bei Bothroponera tesserinoda Forel (Formicidae: Ponerinae). Z. Tierpsychol., 35: 113-123.

Moglich, M., 1978. Social organization of nest emigration in Leptothorax (Hym., Form.). Insectes Sociaux, 25: 205-225. 
MOGlich, M., AND B. Holldobler. 1974. Social carrying behavior and division of labor during nest moving in ants. Psyche, 81: 219-236.

MOGlich, M., AND B. HOLldobler. 1975. Communication and orientation during foraging and emigration in the ant Formica fusca. J. Comp. Physiol., 101: 275-288.

OSTER, G. F., AND E. O. WiLson. 1978. Caste and ecology in the social insects. Princeton.

Pamilo, P., and S. L. Varvio-Aho. 1979. Genetic structure of nests in the ant Formica sanguinea. Behav. Ecol. Sociobiol., 6: 91-98.

Peeters, C. 1982. The reproductive strategy of the ponerine Ophthalmopone berthoudi: an insight into the evolution of ant eusociality. pp. 220-221 in: Breed, M. D., C. D. Michener and H. E. Evans (eds). The biology of social insects. Westview.

Peeters, C. 1984. Social organization, breeding biology, and the process of reproductive differentiation in Ophthalmopone berthoudi Forel, a ponerine ant. Unpublished Ph. D. thesis, Univ. of Johannesburg.

Peeters, C., AND R. Crewe. 1984. Insemination controls the reproductive division of labour in a ponerine ant. Naturwissenschaften, 71: 50-51.

RosengReN, R. 1971. Route fidelity, visual memory and recruitment behavior in foraging wood ants of the genus Formica (Hymenoptera, Formicidae). Acta Zoologica Fennica, 133, 106 p.

Rosengren, R., AND P. Pamilo. 1983. The evolution of polygyny and polydomy in mound-building Formica ants. Acta Entomol. Fennica, 42: 65-77.

Scherba, G. 1964. Analysis of inter-nest movement by workers of the ant Formica opaciventris Emery (Hymenoptera: Formicidae). Anim. Behav., 12: 508-512.

WARD, P. S. 1981. Ecology and life history of the Rhytidoponera impressa group (Hymenoptera: Formicidae). II. Colony origin, seasonal cycles, and reproduction. Psyche, 88: 109-126.

WARD, P. S. 1983. Genetic relatedness and colony composition in a species complex of ponerine ants. I. Phenotypic and genotypic composition of colonies. Behav. Ecol. Sociobiol., 12: 285-299.

Wheeler, W. M. And J. W. Chapman. 1922. The mating of Diacamma. Psyche, 29: 203-211.

WheLdEN, R. M. 1957. Notes on the anatomy of Rhytidoponera convexa Mayr ("violacea" Forel) (Hymenoptera, Formicidae). Ann. Entomol. Soc. Amer., 50: 271-282.

WILsON, E. O. 1971. The insect societies. Harvard, Univ. Press. 

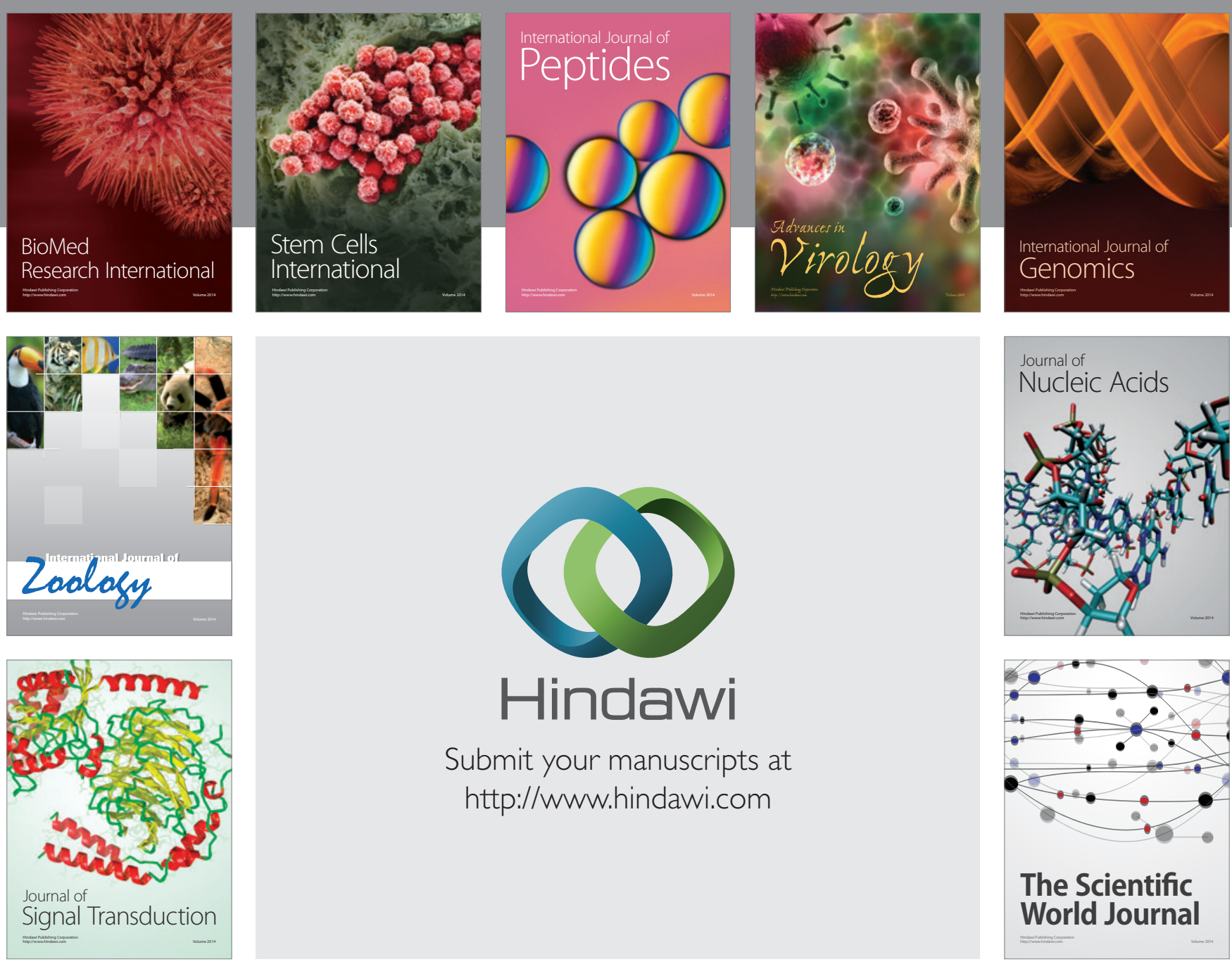

Submit your manuscripts at

http://www.hindawi.com
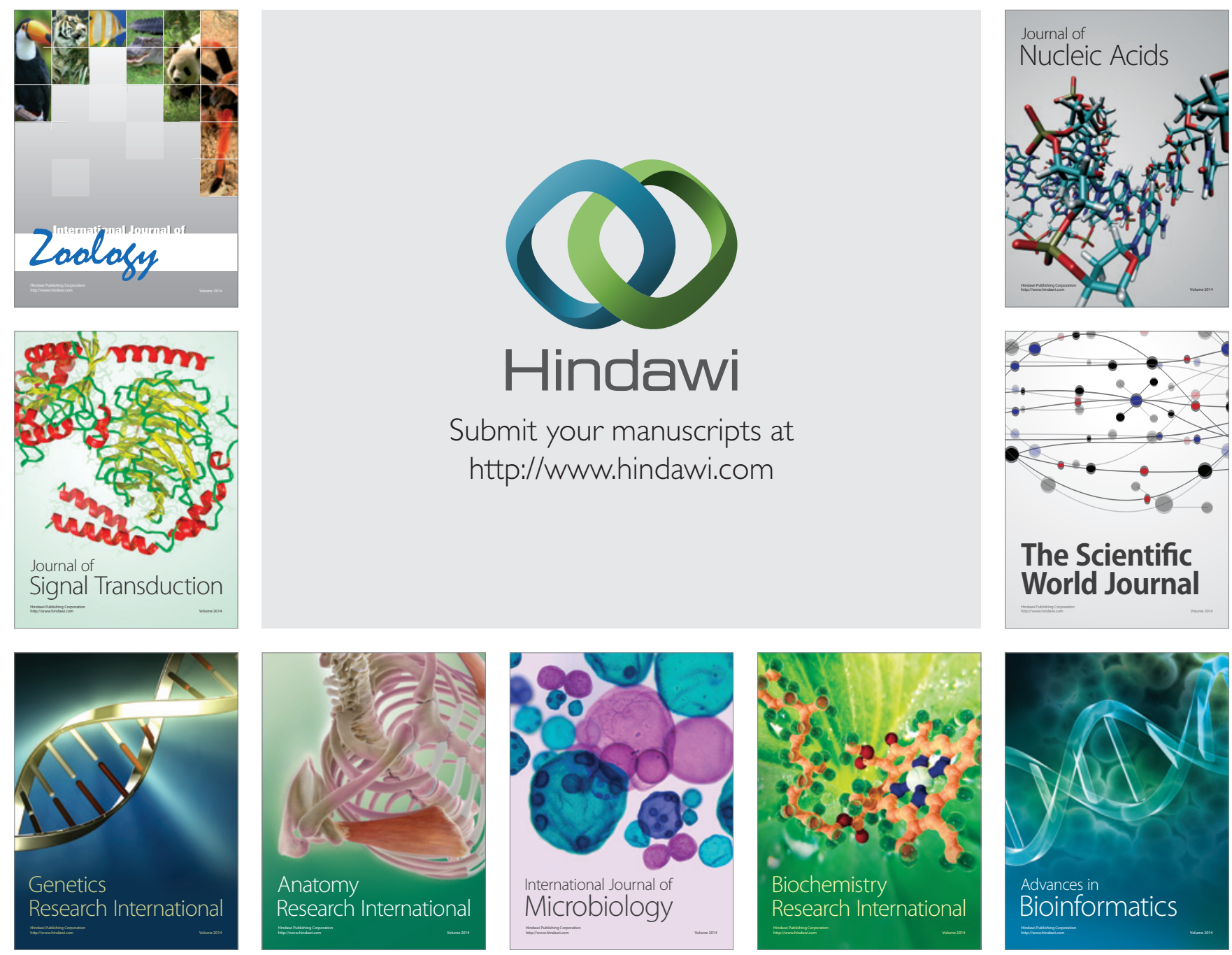

The Scientific World Journal
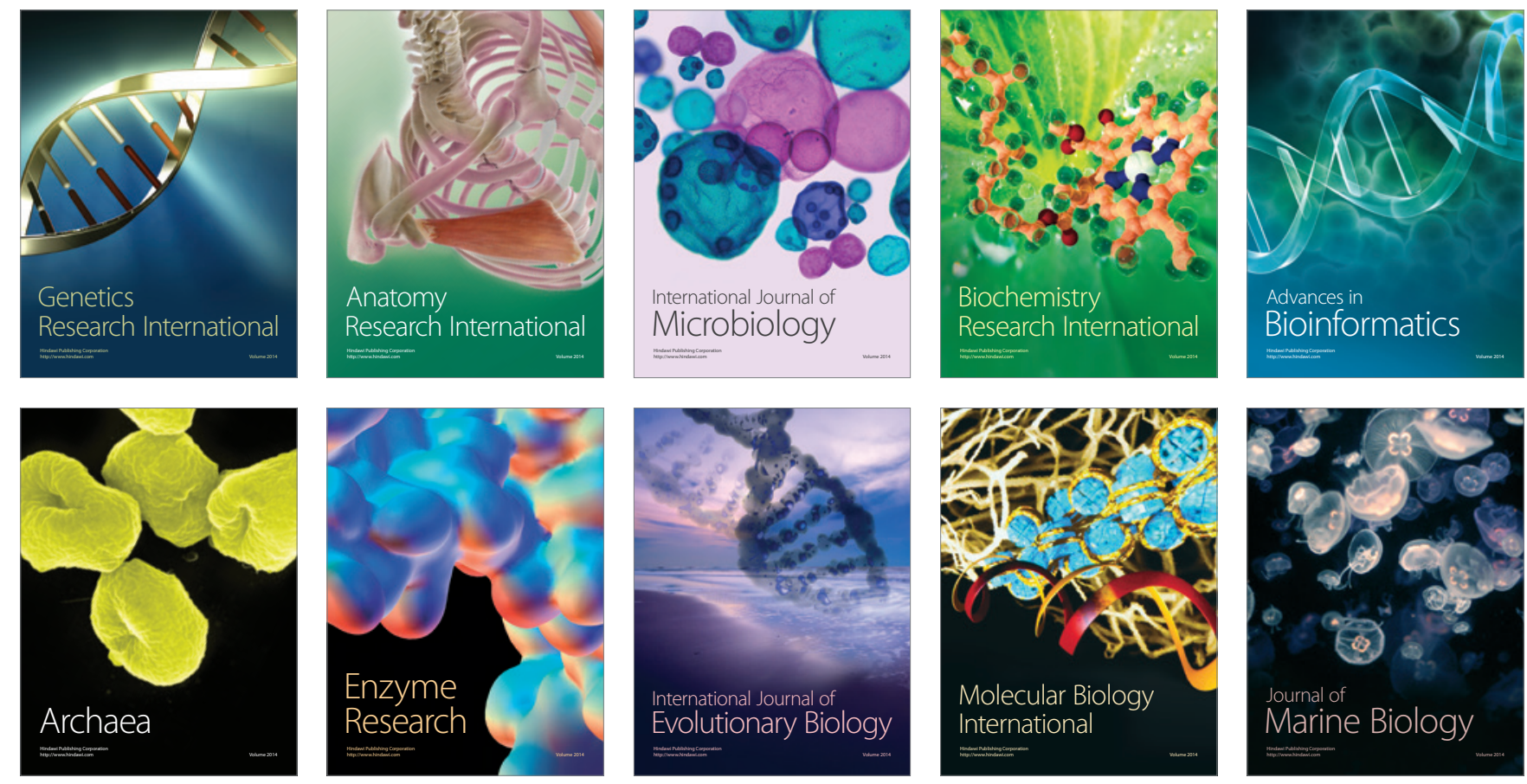